\title{
BUILDING TRUST \\ AMONG THE CLIENTS OF CLOUD \\ COMPUTING INDUSTRY. \\ CASE STUDY OF TRELLO, INC.
}

\author{
Róża Błaś \\ Nicolaus Copernicus University in Toruń, \\ Faculty of Economic Sciences and Management, Toruń, Poland \\ e-mail: roza.blas@gmail.com
}

\begin{abstract}
Purpose: The main objective of this paper is to identify proper practices for building clients' trust by Trello, Inc., aimed to convince potential clients of their cloud-based services.

Approach: In this paper, the case study of Trello, Inc. is used to analyze the case data, aimed to examine the causal links between actions taken to gain clients' trust and their observed effects.

Implications: This paper provides insight into building trust in Business to Business (B2B). Using cloud technologies to offer services enables a company to create innovative value proposition, or in other cases, add new features and attributes to it that cater to the clients' needs. It involves different approach of the company in building clients' trust than if it offered services in traditional way. To handle this issue effective trust management implementation is required.

Findings: This paper provides suggestions of trust management actions which can be taken and are not limited to data security guarantee.

Value of the paper: This paper underlines proper practices - based on the success of Trello, Inc. - for building clients' trust by business where aim is to convince potential clients of enterprise's cloud-based service.
\end{abstract}

Keywords: client trust, trust management, cloud computing, electronic service, software as a service Paper type: Case study

\section{Introduction}

Every year the Internet is getting richer and richer in cloud-based services. Enterprises use benefits which cloud technologies offer to create value proposition in the idea of turning more clients to the company over another. To meet it they extend previous selected bundle of products and services of the ones or create totally new one which has to meet entirely new set of their clients' needs. 
BUILDING TRUST AMONG THE CLIENTS OFCLOUDCOMPUTING

Róża Błaś

\subsection{Motivation}

The broadest definition of cloud computing technology is presented by the National Institute of Standards and Technology. According to it, cloud computing is defined as a "model that enables ubiquitous, convenient, on-demand network access to a shared pool of configurable computing resources (e.g., networks, servers, storage, applications, and services) that can be rapidly provisioned and released with minimal management effort or service provider interaction" (Mell and Grance, 2011). It makes that on the one hand, thanks to its essential characteristics cloud computing is a worthy tool for enterprises in creating innovative value proposition (Chou, 2010). But on the other hand, the small interaction between a client and a cloud-based service provider creates a need of trust in buyer-seller relationships (Kaufman, 2009; Gupta et al., 2014; Noor et al., 2014).

The problem is more apparent in situation when an enterprise aims to reach and serve a segment which consists of other companies (B2B). If the individual or business clients are online, then their data, especially sensitive or behavioral information, is at risk from remote internet-based attacks or any other incidents (Noor et al., 2014). However, in contrast to the individual clients, the business clients are more affected by consequences of data leak, data release or data loss ranging from their customer dissatisfaction to financial ruin and business closure (Mickelberg et al., 2014). Nonetheless, despite mutually inclusive trust and security, in particular, apparent in cloud computing where users are expected to accept the implicit premise of trust in spite of a fear of lack of control over their data, they are two different terms which should not be treated as equivalent words (Kaufman, 2009).

Furthermore, unlike individual clients, in case of business clients more people are engaged in buying decision process which, among other things, causes grater uncertainty (Johnson et al., 1996). It creates a need of strong relationships based on trust (Doney and Cannon, 1997) between a cloud-based service provider and its business client to turn it to the company even if the process of building trust is expensive, time-consuming and complex (Doney and Cannon, 1997). Scientifically, it is nothing new. Long-term company-customer relationships based on strong trust are used, for instance, as a way of overcoming competition in a rapidly changing environment (Dertouzos et al., 1989).

It requires insights into the nature of trust (Doney and Cannon, 1997) which is different depending on customer segments (Anderson and Narus, 1990), and has got substantial impact on type of trust relationships that are being build (Demolombe, 2004). Literature review shows interdisciplinary nature of trust which is complex (Kramer et al., 2010), and taken into account as particular point in different scientific disciplines, including social psychology, sociology, economics and marketing (Doney and Cannon, 1997). Among them trust 
understood as a correct behavior of some entity is a much more common concept than trust understood as a mental attitude (McKnight and Chervany, 1996).

Based on marketing and social psychology literature, in B2B context trust is defined as "the perceived credibility and benevolence of a target of trust" (Kumar et al., 1995). Thus, definition of trust in industrial buying context consists of two dimensions - independent and dependent one (McKnight and Chervany, 1996). The first dimension focuses on the subjective probability by which a given party expects other party to act in a particular order (Jøsang et al., 2005). Meanwhile, second dimension treats trust as the extent to which a given party is eager to rely on other party even if negative consequences of it are possible to occur (Jøsang et al., 2005). Jøsang, Keser and Dimitrakos (2005) by comparing this two definitions of trust to the need of online environment, created following definition of trust management, which is:

The activity of creating systems and methods that allow relying parties to make assessments and decisions regarding the dependability of potential transactions involving risk, and that also allow players and system owners to increase and correctly represent the reliability of themselves and their systems possible.

Therefore, to build trust in buyer-seller relations two parties are required where one party on the basis of source of trust (Doney and Cannon, 1997) needs to know (strong trust) or at least believes (weak trust) that second party behaves correctly as it is expected (Morris and Vines, 2014; Hosking, 2014).

There is a lot of literature on a concept of trust which has broad and complex nature (Doney and Cannon, 1997) depending on customer segments, and involves 5 cognitive processes as follows: calculation, prediction, capability, intentionally, transference (Doney and Cannon, 1997). However, very few researchers do attempt to apply it in the context of offering cloud-based services. It convinced the author of this paper to study this issue on the basis of a case of Trello, Inc.

\subsection{Goal}

Searching the Internet for electronic services gives a lot of engine results of companies which offer cloud-based services. Of course, every business runs differently and with different results. Here Trello, Inc. (further also referred to as 'enterprise') headquartered in New York, which reached 12 million clients in less than six years, seems to be particularly noteworthy for its success. The company offers an application operating under the same name (further also referred to as 'Trello') centered on Kanban system (Wan et al., 2009), and designed to enhance communication between company's employees and facilitate projects and tasks management within it.

Focusing on the success of Trello, Inc. this paper examines its effective trust management in building respected and successful brand. The goal of this article is to gain helpful insights into how a company, which offers cloud-based services,
BUILDING TRUST AMONG THE CLIENTS OFCLOUDCOMPUTING

Róża Błaś 
BUILDING TRUST AMONG THE CLIENTS OFCLOUDCOMPUTING

Róża Błaś can build trust among potential clients. Therefore, two hypotheses were tested by this case study, and they were as follows:

1) the possibility to co-create a value proposition impacts positively clients' trust towards the company which provides cloud-based service,

2) the lack of transparency on security issues of the company providing cloud-based service impacts negatively clients' trust.

To set the stage, in the following sections each detail of building clients' trust by Trello, which provides a solid base in this issue, is discussed. In that context, section 2 describes research method by which the case study was produced. Next, section 3 shows all the observations outlining Trello, Inc. business model, selected problems of building clients' trust which it may entail and activities taken by Trello, Inc. in order to solve them. In section 4 results of this case study of Trello, Inc. are presented. The author argues that data security is not the key challenge and other aspects of building clients' trust deserve much more attention. Section 5 offers conclusions highlighting main points which company should focused on when building potential clients' trust, and therefore gaining more clients as a result.

\section{Methods}

For the purpose of this paper real-world situation was studied. To test the conditions under which hypotheses were given, a single-case study was applied as a research method in which a 'case' is Trello. To carry out this web survey, the internet-based methods were used. Thus, delegated Trello employee was interviewed. To meet the interviewee - because of distance - semi-structured interview by Skype was conducted. The author also reviewed online data created by the main unit of analysis in order to raise awareness among the clients about the enterprise's value proposition. Besides that, direct observations were made by the author of this paper. Furthermore, the author interviewed 10 Polish potential Trello's corporate clients, and 10 selected foreign corporate clients who pay for premium service. To collect the data from interviewees, semi-structured face to face as well as web interviews were conducted.

To add precision to the analysis, already created theory of trust and trust management were used. Moreover, the business model canvas template was used (Osterwalder and Pigneur, 2009) to embed best practices of building clients' trust in business model.

\section{Research}

Trello application was launched in 2011 at TechCrunch Disrupt (Lomas, 2014), and then, it was spun into a separate company in 2014 by taking in funding $\$ 10.3$ million (Gage, 2014). However, when the flood gates really began to open, Trello's employees noticed two barriers: price and language. In those early days they put 
some effort to create business model which is significantly concentrated on value proposition and cooperation with users.

\subsection{Trello, Inc. business model}

On one hand, Trello as an enterprise is an example of a freemium business model focused on mass market which nowadays is very popular among web-based companies (Mizuno and Odake, 2016). But on the other hand, Trello as a product is a consumer-centered software as a service running on public cloud, wherein the cloud infrastructure is owned, managed and operated by Amazon. From the beginning Trello was accessible from web browsers. Nowadays, to support users to gain access to Trello from a variety of sources, apart from web, the software is also available on mobile devices with iOS, Android and Windows Phone system. Thereby, users gain access to uploaded data regardless of where they are, and the access is only limited to the possession of telecommunication devices which have internet connection. It represents basic characteristics of cloud-based services (Mell and Grance, 2011).

The insight of Trello's business model, placed on canvas template, is presented in Figure 1. According to the data, the application is catered to individual clients as well as companies. On top of that, the customer segments are seen on revenue model. There is one free basic version of Trello and two payable premium ones which provide users additional features what the clients can use to calculate cost of the enterprise's cheating (Doney and Cannon, 1997). The assumption was that individual users, who would be delighted after using Trello, will invite their workmates to use it as a tool to manage common projects they are engaged in, and maybe further down the line to convince companies they work for to launch the software in premium version into company's structure (Johnson et al., 1996). According to that kind of model, small group of paying clients finance a large group of non-paying clients who use free version of Trello what proves that Trello, Inc. business model represents freemium pattern (Anderson, 2009; Christensen, 2015). As a result, money is actually being made by companies as clients.

Trello was available worldwide from the start, but initially only in English language. Therefore, decision was made to prep Trello for international market and make it accessible for Portuguese, Spanish and German users. Next, Trello was translated into French. At that time, the enterprise decided to use crowdsourcing instead of professional translator. To make it work, they encouraged users who were familiar with Trello to voluntarily contribute translations which was not much different from what Google did with Wikipedia with its open source articles (Reagle, 2010). Since that time great amount of user-driven content was created. Currently Trello is translating using this model into sixteen languages. However, Trello, Inc. experience shows that offering cloud-based service in potential clients' mother language is not the core thing which can help build trust anyhow and
BUILDING TRUST AMONG THE CLIENTS OFCLOUDCOMPUTING

Róża Błaś 
BUILDING TRUST AMONG THE CLIENTS OFCLOUDCOMPUTING

Róża Błaś convince them to use the service. Only once they conducted marketing campaign in Portuguese market, Trello, Inc. started to reach Portuguese clients.

Nevertheless, this way of engaging users in providing small help in creating value proposition is still maintained in different fields. The users are also involved in facilitating application of new functionalities. For instance, Trello, Inc. employees create collaboration boards within the application to manage tasks, aimed at making Trello much more fine-tuned software which meets their clients' needs. These boards also play a role of platform to discuss and understand better needs and behavior of both sides (Macneil, 1980), and to build closer interpersonal relations between the users of this digital tool and the Trello employees who represent a source of trust for the users (Doney and Cannon, 1997). On top of that, there are endorsement-like boards created by Trello, Inc. team or involved users to make every user more familiar with the application and instruct it in the use of this tool before they decide to do it (Doney and Cannon, 1997).There are also social media pages dedicated to reach out to the potential or current clients. Trello social accounts can be found on Facebook, Twitter, LinkedIn and YouTube, and they are used to create content about Trello application which shows various ways of using this tool. In this case very helpful is Trello Blog. Users can find on it some life hacks and inspiration for using Trello which can encourage them to dabble with it and inform about updates or solutions of solving out selected technical problems to bolster their own digital skills. At the same time, social media platforms are used by the Trello users to ask for help, share their opinion, or get to know experience of other users in cooperation with Trello, Inc., and in consequence, infer the trustworthiness of Trello, Inc. (Milliman and Fugate, 1988). As a result, Trello, Inc. employees on behalf of the enterprise provide potential clients with valuable information long before they decide to use their services (Doney and Cannon, 1997).

Value proposition, presented above, is created by the web site at www. trello.com. This is the most important asset of Trello business model. Thanks to this key resource Trello, Inc. can reach the market, build relations with clients, give customer service and generate revenue. This key resource impacts key activities which the enterprise needs to include into its business model to run it well (Osterwalder and Pigneur, 2009). The key activities mentioned above are: development and maintaining of platform and software.

This business model, presented in Table 1, designed with the platform and software helps to maintain self-service (Mell and Grance, 2011). Despite that, building relations is still significant to make this business model work. That is why Trello, Inc. is building online community focused around the application which has ability to put noticeable impact on value proposition (Doney and Cannon, 1997). Along with satisfied clients Amazon should be pointed out as a key partner. It provides cloud infrastructure on which Trello application is running. It 
automatically provides computing power appropriately to consumer demand, but at the same time it introduces some barriers on issues like data privacy and lack of data control.

\subsection{Data safety}

Data safety seems to play significant role in offering cloud-based services (Kaufman, 2009). However, the interviews with Polish and foreign Chief Executive Officers (CEOs) showed different arguments, mentioned by both sides, which in their mind are trumping Trello-like cloud-based services. For Polish CEOs (10 out of 10 interviewed) the problem lies in the fact that Trello is a cloud-based tool which works on third-party's servers what diminish the company control over uploaded data, and the application is not available in Polish language what could help them make an assessment of the reliability on a cloud-based service provider and its systems (Jøsang et al., 2005). Meanwhile, foreign CEOs (8 out of 10 interviewed), by contrast, claimed that the only thing which can convince them to use given application, among others, is to provide them directly with all information needed to understand to operate it and fast customer service (Doney and Cannon, 1997).

The undermentioned shows practices taken by Trello, Inc. in context of data security. To run the business Trello, Inc., among other things, protects personal privacy based on the principles of EU-U.S. Privacy Shield which superseded Safe Harbor Framework, protects copyright law based on Digital Millennium Copyright Act, and applies U.S. Children's Online Privacy Protection Act (COPPA).

Trello, Inc. collects two types of information as long as an account is active which refers to individual - personal information and sensitive personal information which are uploaded by every user directly or indirectly during the time of using the application. In the latter case, Trello gathers both non-personallyidentified and potentially personally identifying. Moreover, the clients who want to choose one of the payable versions of Trello need to provide financial and more detailed personal information, including valid billing data.

To use Trello every user needs to sign up for Trello services to create a valid cyber identity. By doing it, every user consents to Trello Terms of Service and Trello, Inc. Privacy Policy. According to Trello, Inc. Privacy Policy, the users can upload within their account differential content such as text, photographs, videos and audio clips, and have access to the entered data at any time, aimed at correct it, update, modify or delete when needed. In Terms of Service Trello, Inc. clearly emphasizes that content provided by the users solely belongs to them, and they have exclusive responsibility for the entered content. As a result, every situation of belief that copyrighted work is infringed can be reported to the dedicated Trello's Digital Millennium Copyright Act Agent. Furthermore, the users are also responsible for an unauthorized access to the website or mobile
BUILDING TRUST AMONG THE CLIENTS OFCLOUDCOMPUTING Róża Błaś 
BUILDING TRUST AMONG THE CLIENTS OFCLOUDCOMPUTING

Róża Błaś application, unauthorized use of corporate resources, and their disclosure or loss, if the situation raised from their failure.

The clients' rights and responsibilities are listed in Trello Terms of Service, and Trello, Inc. Privacy Policy which implementation and respecting is actively monitored and ensured by the Trello, Inc. Data Protection Officer. However, the users need to confirm that the principles mentioned in the documents, which can be changed at any time by Trello, Inc., are applicable to them, based on their national regulations.

\section{Discussion}

When considering business model pattern, based on customer relationships which are driven by corporate clients' acquisition, it should evolve ground up from basic value proposition to value proposition developed voluntarily by satisfied users. Here the bottom line seems to be strong relationships with individual users as key partners who are eager to co-create the cloud-based offer and recommend it to the companies they work for when taking part in buying decision process (Johnson et al., 1996).

\subsection{Co-creating a value proposition}

Based on Trello, Inc. practices, one of the key findings is that opposed to traditional marketing where the communication is one-way - the cloud-based service provider should create cyberspace platforms to interact with users (Macneil, 1980). Thanks to that, clients have access to the information about the company's past promises as well as behavior and whether its commitments' were fulfilled or not (Milliman and Fugate, 1988). Based on it the clients can improve their ability to predict the company's future behavior. Furthermore, the company has got better control over the flow of information on the line customercompany. Meanwhile, the lack of such kind solution might involve more resources and devote more time to simple task which might slow down the communication with users, and then in return, damage the brand (Kumar et al., 1995). That way Trello, Inc. use repeated interaction as well as courtship as a source of developing trust of a buying client (Lewicki and Bunker, 1995).

Moreover, the findings indicate that the cloud-based service provider should provide the users with the software developed in the direction they expect it to. As a result, both parties develop shared values (Macneil, 1980), and in consequence, each party understands better the other party's behavior (Doney and Cannon, 1997). Thus, to get large enough group of brand's supporters which will talk about the service, the company should reach to the users with impressive content providing valuable information which, then, encourages them to take further actions to co-create the application and to promote it on the basis of their experience (Doney and Cannon, 1997). To gain it, the cloud-based service 
provider should provide the users with incentive and means to communicate by creating the right environment in which they are able and willing to discuss their services (Jucks et al., 2016). In that way users cooperate directly with the company's employees - people who stand behind the brand and make important source of trust for the clients (Doney and Cannon, 1997). Thereby, users can get faster response to their questions or propositions about the service, instead of waiting for a long time for answers. On top of that, both sides know exactly who they communicate with what, again, is much more personal approach so rare and so needed in today's customer service, and helps evaluate credibility of the information (Jucks et al., 2016).

Results of such kind of marketing activities, proven by 12 million clients reached by Trello, Inc. worldwide in less than 6 years of running business, confirm the hypothesis that the possibility to co-create a value proposition impacts positively clients' trust towards a company which provides cloud-based service.

\subsection{Transparent security issues}

The comparison of the findings about Trello, Inc. data security policy with 12000000 Trello users do not confirm the hypothesis that the lack of transparency on security issues of a company providing cloud-based services impacts negatively clients' trust. However, it is noteworthy that in case of cloud-based services access to valuable information and consultation (Doney and Cannon, 1997) should not predominate any legal agreement weaknesses. The documents which according to Trello, Inc. suppose to describe clients' main rights and responsibilities such as term of service and privacy policy do not include information which might answer all clients' questions about security concerns, and most likely do not dispel their doubts. Consequently, it might lower assessment of a supplier (Doney and Cannon, 1997). Here important suggestion seems to be practice of using service level agreement as a legal agreement, instead of terms of service with fixed principles which can be accepted by an unlimited number of users what, in return, provides ample room for an interpretation.

Moreover, Trello Terms of Service shifts the responsibility to the clients for complying the document with current nationally requirements governing the use of computers and information. Of course, every user can contact Trello, Inc. in any cases, including data protection. Nevertheless, developing trust depends not only on company's employees who have contact with clients, but also on the company's policy (Doney and Cannon, 1997). Thus, efforts to save clients' data cannot be limited only to the software safety, but they should be also extended to include implementation of national requirements that one party must respect in terms of legal rights (Kaufman, 2009). Especially that business clients are obligated by law to keep their customer information secure.
BUILDING TRUST AMONG THE CLIENTS OFCLOUDCOMPUTING

Róża Błaś 
BUILDING TRUST AMONG THE CLIENTS OFCLOUDCOMPUTING

Róża Błaś

\section{Conclusion}

Nowadays the market of digital tools is very crowded. A plethora of uniquely designed applications for managing projects are available. Thanks to that, every Internet user can match it up to its needs and make it a component of everyday life. Here the bottom line seems to be clients' trust towards a company which offers cloud-based service, and thereby stores its clients' data. Even if it does not seem to be as an important issue for an individual client like it is for the case of corporate ones, it makes so that building trust among individual clients translates into corporate clients' trust.

The case study of Trello, Inc. underlines what seems to be the best practices which should be taken to build trust among clients of cloud-based services based on 5 processes of developing trust (Doney and Cannon, 1997).

Firstly, in this type of self-service offers the company needs to segregate its customers and establish company-customer relationships which integrates with specified business model. Good way to achieve this by the company which offers service as a software seems to be going beyond traditional customer-vendor relationship. The company aimed to build customer relationships driven by boosting sales should create and nurture community and utilize it to co-create value proposition.

Secondly, the company needs to provide users with necessary information about a cloud-based service and multi-channel contact which represents a reassuring solution of quick response. Worth remembering is that the company should inform their clients about its data security plan implemented through due care and due diligence (Kaufman, 2009) to allow them to make assessment and decision about using cloud-based service (Jøsang et al., 2005).

In summary, giving users the ability to impact and co-create value proposition to adapt it to their needs plays more beneficial role in building trust to a company, than company's assurances on security issues. A client should be sure that a cloud-based service is not a still stand application, but the one which will be developed according to the said clients' needs. In essence, an active multi-channel communication between a client and a company which offer cloud-based service must be maintained.

Nonetheless, the study also shows that different practices are necessary to build trust among clients depending on the nationality of users. Therefore, further research in that area is required, considering different methods which can precisely measure it.

\section{References}

Anderson, C. (2009), Free: The past and future of radical price, Hyperion, New York. Anderson, J. C., Narus, J. A. (1990), "A Model of Distributor Firm and Manufacturing 
Firm Working Partnerships”, Journal of Marketing, Vol. 54 No. 1, pp. 42-58. DOI: http://dx.doi.org/10.2307/1252172

Chou, T. (2010), Introduction to Cloud Computing: Business and Technology, Active Book Press, Madison.

Christensen, J. (2015), Digital Business in the Digital Age, Books on Demand, Copenhagen.

Demolombe, R. (2004), "Reasoning about trust: A formal logical framework. Proceedings of the Conference on Trust Management", available at: http://www.irit.fr/ Robert. Demolombe/ publications/2004/itrust04.pdf (accessed 19 January 2016).

Dertouzos, M. L., Lester, R. K., Solow, R. M. (1989), Made in America: Regaining the Productive Edge, The MIT Press, Cambridge.

European Commission (2016), "EU Commission and United States agree on new framework for transatlantic data flows: EU-US Privacy Shield", available at: http://europa. eu/rapid/press-release_IP-16-216_en.htm (accessed 25 March 2016).

Hosking, G. (2014), Trust. A history, Oxford University Press, New York.

Johnson, W. J., Lewin, J. E. (1996), "Organizational Buying Behavior: Toward an Integrative Framework", Journal of Business Research, Vol. 35 No. 1, pp. 1-15. DOI: http:// dx.doi.org/10.1016/0148-2963(94)00077-8

Jøsang, A., Keser, C., Dimitrakos, T. (2005), “Can We Manage Trust?”, available at: http:// folk.uio.no/josang/papers/JKD2005-iTrust.pdf (accessed 1 March 2016).

Gage, D. (2014), "Digital Whiteboard Trello Spins Out of Fog Creek With \$10.3M", available at: http://blogs.wsj.com/venturecapital/2014/07/24/digital-whiteboardtrello-spins-out-of-fog-creek-with-10-3m (accessed 8 March 2016).

Gupta, S., Kumar, P., Abraham, A. (2014), "Cloud Computing: Trust Issues, Chellenges, and Solutions", in: Sabu, M. T., Bharat, B., Pradeep, K. A. (Eds.), Managing Trust in Cyberspace, Chapman and Hall/CRC, London, pp. 13-40.

Hosking, G. (2014), Trust. A history, Oxford University Press, New York.

Jucks, R., Linnemann, G. A., Franziska, M. T., Zimmermann, M. (2016), “Trust the Words: Insights into the Role of Language in Trust BUilding in a Digitalized World", in: Blöbaum, B. (Ed.), Trust and Communication in a Digitized World. Models and Concepts of Trust Research, Springer, London, pp. 225-238.

Kaufman, L. M. (2009), "Data security in the world of cloud computing", IEEE Security \& Privacy, Vol. 7 No. 4, pp. 61-64. DOI: http://dx.doi.org/10.1109/MSP.2009.87

Kramer, S., Goré, R., Okamoto, E. (2010), "Formal definitions and complexity results for trust relations and trust domains", ACM SIGACT, Vol. 41 No. 1, pp. 122-147. DOI: http://dx.doi.org/10.1145/1753171.1753193

Kumar, N., Scheer, L. K., Steenkamp, J. E. M. (1995), "The Effects of Perceived Interdependence on Dealer Attitudes", Journal of Marketing Research, Vol. 32 No. 3, pp. 348-356. DOI: http://dx.doi.org/10.2307/3151986

Lewicki, R. J., Bunker, B. B. (1995), “Trust in Relationships: A Model of Development and Decline", in: Bunker, B. B., Rubin, J. Z. (Eds.), Conflict, Cooperation, and Justice: Essays Inspired by the Work of Morton Deutsch, Jossey-Bass, San Francisco, pp. $133-173$.

Lomas, N. (2014), "Disrupt Alum Trello Takes In \$10.3M For Its Visual To-Do Lists",
BUILDING TRUST AMONG THE CLIENTS OFCLOUDCOMPUTING

Róża Błaś 
BUILDING TRUST AMONG THE CLIENTS OFCLOUDCOMPUTING

Róża Błaś available at: http://techcrunch.com/2014/07/24/trello-series-a (accessed 10 March 2016).

Macneil, I. R. (1980), The New Social Contract, Yale University Press, New Haven.

McKnight, D. H., Chervany, N. L. (1996), "The meanings of trust”, available at: http:// www.misrc.umn.edu/workingpapers/fullpapers/1996/9604_040100.pdf (accessed 18 February 2016).

Mell, P., Grance, T. (2011), "A NIST Definition of Cloud Computing”, available at: http:// csrc.nist.gov/publications/nistpubs/800-145/SP800-145.pdf (accessed 15 February 2016).

Mickelberg, K., Pollard, N., Schive, L. (2014), "PricewaterhouseCoopers LLP, US cybercrime: Rising risks, reduced readiness. Key findings from the 2014 US State of Cybercrime Survey", available at: http://www.pwc.com/en_US/us/increasingit-effectiveness/publications/assets/2014-us-state-of-cybercrime.pdf (accessed 18 December 2016).

Milliman, R. E., Fugate, D. (1988), "Using Trust-Transference as a Persuasion Technique: An Empirical Field Investigation”, Journal of Personal Selling and Sales Management, Vol. 8 No. 2, pp. 81-101. DOI: http://dx.doi.org/10.1080/08853134.1988.107 54486

Mizuno, Y., Odake, N. (2016), "A case study of progressive formation of accounting cloud services in Japan", International Journal of Service Science, Management, Engineering, and Technology, Vol. 7 No. 3, pp. 406-425. DOI: http://dx.doi.org/10.4018/ IJSSMET.2016070102

Moor, J. (2006), "Why we need better ethics for emerging technologies", Ethics and Information Technology, Vol. 7 No. 3, pp. 111-119. DOI: http://dx.doi.org/10.1007/ s10676-006-0008-0

Morrsi, N., Vines, D. (2014), Capital failure. Rebuilding trust in financial services, Oxford University Press, New York.

Noor, T. H., Sheng, Q. Z., Bouguettaya, A. (2014), Management in Cloud Services, Springer, Cham.

Osterwalder, A., Pigneur, Y. (2009), Business Model Generation: A Handbook for Visionaries, Game Changers, and Challengers, Modderman Druckwerk, Amsterdam.

Reagle, J. M. (2010), GOOG FAITH COLLABORATION. The Culture of Wikipedia, The MIT Press, Massachusetts.

Wan, H., Shukla, S. K., Chen, F. F. (2009), "Pulling the Value Streams of a Virtual Enterprise with a Web-based Kanban System", in: Wang, L., Nee, Y. C. (Eds.), Collaborative Design and Planning for Digital Manufacturing, Springer, London, pp. 317-340. 